\section{Speech-Language Therapy}

Roberta Depompei

School of Speech-Language Pathology and Audiology, University of Akron, Akron, OH, USA

\section{Synonyms}

Speech-language intervention

\section{Definition}

Speech-language therapy is the variety of processes employed by speech-language pathologists who work with the full range of human communication and its disorders. Treatment areas include speech, language, cognitive communication, or swallowing disorders in individuals of all ages, from infants to the elderly. Speech-language therapy includes multiple techniques that induce change in communication skills of patients. Therapy can be impairment-based, focusing on the management of contingent relations between antecedents, responses, and consequences of the communication attempt, or participation-based, focusing on manipulating pragmatic social communication interactions among the speaker, listener, and environment. For example, if working from an impairment-based model, the therapy would be directed toward helping the individual formulate better-sounding words and sentences or increasing reading or writing skills. If working from a social communication participation-based model, the therapy would include significant communication partners in real environments and would focus on helping the client be understood in any environment by any communication means possible. Compensatory strategies such as assistive technology could also be employed.

\section{Cross-References}

Speech-Language Pathology

\section{References and Reading}

Papathanasiou, I., Coppens, P., \& Potagas, C. (2013). Aphasia and related neurogenic communication disorders. Burlington: Jones and Bartlett Learning.

Roth, F., \& Worthington, C. (2005). Treatment resource manual for speech-language pathology. New York: Cengage/Thompson Learning.

www.asha.org/student.speechlanguagepathology 